\title{
Relationship Between Adiposity and Body Size Reveals Limitations of BMI
}

\author{
Alan M. Nevill, ${ }^{1 \star}$ Arthur D. Stewart, ${ }^{2}$ Tim Olds, ${ }^{3}$ and Roger Holder ${ }^{4}$ \\ ${ }^{1}$ Research Institute of Healthcare Sciences, University of Wolverhampton, WS1 3BD Walsall, UK \\ ${ }^{2}$ School of Health Sciences, The Robert Gordon University, AB10 7QG Aberdeen, Scotland, UK \\ ${ }^{3}$ Centre for Applied Anthropometry, School of Health Sciences, University of South Australia, Underdale, \\ SA 5001 South Australia, Australia \\ ${ }^{4}$ Department of Primary Care and General Practice, University of Birmingham, B15 2TT Birmingham, UK
}

\author{
KEY WORDS anthropometry; skinfold; proportional allometric; MANCOVA; ANCOVA
}

\begin{abstract}
The aims of this study were to assess 1 ) whether the stature-adjusted body mass index (BMI) is a valid proxy for adiposity across both athletic and nonathletic populations, and 2) whether skinfold measurements increase in proportion to body size, thus obeying the principle of geometric similarity. The research design was cross-sectional, allowing the relationship between skinfold calliper readings (at eight sites and between specific athletic and nonathletic groups, $\mathrm{n}=478$ ) and body size (either mass, stature, or both) to be explored both collectively, using proportional allometric MANCOVA, and individually (for each site) with follow-up ANCOVAs. Skinfolds increase at a much greater rate relative to body mass than that assumed by geometric similarity, but taller subjects had less rather than more adiposity, calling into question the use of the traditional skinfold-stature adjustment, 170.18/stature. The best
\end{abstract}

There can be no doubt that people in the Western world are getting fatter. Indeed, some authors refer to this trend in increasing fatness as an "obesity epidemic" (Davey and Stanton, 2004; Jeffreys et al., 2003; Popkin, 2001). Clearly, there is a need to monitor these systematic changes in fatness, using reliable and valid measures of adiposity. In population studies, the two most commonly reported indices of fatness or obesity are 1) body mass index (BMI = body mass/stature ${ }^{2}$ ), where body mass and stature are recorded in kilograms $(\mathrm{kg})$ and meters $(\mathrm{m})$, respectively, and 2) relative adiposity, commonly estimated either by waist/hip girth ratios or from summing measurements of raised skinfolds.

Numerous studies investigated the relationship between body fat and stature-adjusted body mass with a view to obtaining a simple index to identify the overweight or obese members of the community (reviewed in Cole, 1991). In such studies, BMI emerges as the overwhelming favorite. Despite its convenience and popularity, some researchers still consider BMI a relatively crude index of adiposity, predominantly due to the fact that it fails to quantify body composition. Indeed, healthy adults can be misdiagnosed by BMI as overweight or obese, if fat mass is verified by a criterion method (Hortobagyi et al., 1994). For instance, a slender-framed female with significant excess fat may appear as a false negative, and a muscular male as a false positive. However, there appears to be little research into whether BMI is a valid and reliable proxy for adiposity across athletic and nonathletic populations.

The utility of surface anthropometry has enabled it to become established as a pivotal technique in estimating body-size index reflective of skinfold measurements was a stature-adjusted body mass index similar to the BMI. However, sporting differences in skinfold thickness persisted, having controlled for differences in body size (approximate BMI) and age, with male strength- and speed-trained athletes having significantly lower skinfolds (32\% and $23 \%$, respectively) compared with controls. Similarly, female strength athletes had 29\% lower skinfold measurements compared to controls, having controlled for body size and age. These results cast serious doubts on the validity of BMI to represent adiposity accurately and its ability to differentiate between populations. These findings suggest a more valid (less biased) assessment of fatness will be obtained using surface anthropometry such as skinfolds taken by experienced practitioners following established procedures. Am J Phys Anthropol 129:151-156, 2006. ๑2005 Wiley-Liss, Inc. total body composition and in describing body shape. Using measurements of raised skinfolds exposed to a standard closing pressure, over 100 skinfold equations were constructed to predict total percent fat, validated against other methods, most commonly densitometry. These are specific to the samples used for measurement or validation, e.g., children, anorexics, females, or members of specific ethnic groups (Heyward and Stolarczyk, 1996). The dual assumptions that skinfold sites represent surface adiposity, and that surface adiposity represents total adiposity, are implicit in the methodology.

Both BMI and skinfolds are encompassed in a further measurement system known as "somatotype," the physique-rating schema popularized by W. Sheldon in the 1940s. Using a combination of stature, total mass, girths, skinfolds, and bone breadths, a three-dimensional numerical description of human physique can be constructed to describe human adiposity, muscularity, and linearity, each thought to be independent of size (Heath and Carter,

*Correspondence to: Professor Alan M. Nevill, Research Institute of Healthcare Sciences, University of Wolverhampton, Walsall Campus, Gorway Road, Walsall WS1 3BD, UK.

E-mail: a.m.nevill@wlv.ac.uk

Received 9 September 2004; accepted 13 January 2005.

DOI 10.1002/ajpa.20262

Published online 3 November 2005 in Wiley InterScience (www.interscience.wiley.com). 
TABLE 1. Physical characteristics $\left(\right.$ mean $\pm s^{1}$ ) of the control and athletic groups by sex

\begin{tabular}{|c|c|c|c|c|c|c|c|c|c|c|c|c|c|c|}
\hline \multirow[b]{2}{*}{ Groups } & \multicolumn{7}{|c|}{ Male } & \multicolumn{7}{|c|}{ Female } \\
\hline & $\mathrm{n}$ & Age & $\mathrm{s}$ & Mass & $\mathrm{s}$ & Stature & $\mathrm{s}$ & $\mathrm{n}$ & Age & $\mathrm{s}$ & Mass & $\mathrm{s}$ & Stature & $\mathrm{s}$ \\
\hline Control & 95 & 30.0 & 9.6 & 75.2 & 9.2 & 178.5 & 8.2 & 104 & 30.2 & 8.8 & 61.7 & 8.7 & 166.0 & 6.1 \\
\hline Endurance & 21 & 31.7 & 10.2 & 76.0 & 12.4 & 176.6 & 5.8 & 26 & 34.5 & 8.6 & 57.3 & 5.3 & 165.2 & 5.3 \\
\hline Games & 47 & 28.1 & 9.7 & 80.8 & 13.1 & 184.7 & 11.4 & 44 & 25.5 & 8.1 & 63.6 & 10.3 & 170.7 & 10.3 \\
\hline Speed & 96 & 24.8 & 4.9 & 91.5 & 14.6 & 184.2 & 8.0 & 12 & 23.6 & 6.2 & 58.3 & 7.7 & 167.1 & 6.2 \\
\hline Strength & 28 & 28.0 & 6.6 & 86.7 & 11.4 & 178.7 & 6.5 & 5 & 25.5 & 7.6 & 55.3 & 6.9 & 167.3 & 6.5 \\
\hline Total & 287 & & & & & & & 191 & & & & & & \\
\hline
\end{tabular}

${ }^{1} \mathrm{~s}=$ standard deviation.

1967). Thus, each descriptor has a size-adjustment built into the calculation, and in the case of skinfolds, this is achieved by multiplying skinfolds by 170.18 /stature (Carter and Heath, 1990).

This size-adjustment approach originally proposed by Ross and Wilson (1974) was used to explore proportional differences in body dimensions from a reference or "phantom" value, using derived z-scores calculated from large data assemblies. However, their objective was to construct a calculation scaling device which was sample-independent, to enable proportional differences between groups to be quantified. Unfortunately, while stressing that the phantom was arbitrary and not a norm, at no time did the authors empirically test the assumption that body-size dimensions increase proportionally with body size, i.e., whether subjects' body-size dimensions are geometrically similar to each other. Note that if we assume that subjects' body-size dimensions are geometrically similar to each other, individual body components (e.g., homologous muscles, hearts, and lungs) should have masses proportional to body mass (M), cross-sectional or surface areas proportional to $\mathrm{M}^{0.67}$, and linear dimensions, such as heights or limb girths, proportional to $\mathrm{M}^{0.33}$.

Hence, the purpose of this study was to investigate the relationship between adiposity (based on measurements of raised skinfolds) and body-size dimensions to assess whether: 1) the skinfold correction 170.18/stature is appropriate to apply across different athletic and nonathletic populations; 2) skinfold measurements increase in proportion to body mass (M), obeying the principle of geometric similarity; and 3) the stature-adjusted BMI accurately reflects adiposity across both athletic and nonathletic populations.

\section{METHODS Subjects}

All subjects $(\mathrm{n}=478)$ were adults (18 years or over), and included untrained controls, and athletes in a variety of sports competing at club, regional, and national levels. They were measured by anthropometrists accredited by the International Society for the Advancement of Kinanthropometry (ISAK), either at the Universities of Aberdeen, UK, or South Australia. Such accreditation enables the error of replicate measures made by a recorder to be quality-assured, which in the case of skinfolds in the present study was not to exceed a 5\% technical error of measurement (TEM). All measurements were made subject to informed consent and in accordance with the ethical requirements of the local institutions.

The physical characteristics (mean \pm standard deviation) of the subjects, by training status and sex, are given in Table 1 . Note that the geometric similarity of the same subjects' girth measurements were reported previously (Nevill et al., 2004). Healthy male and female subjects were classified according to training status (athlete vs. control), with athletes being further subdivided according to type of sport (endurance, e.g., orienteering; speed, e.g., long jumping; strength, e.g., power lifting; and other games, e.g., predominantly team games such as netball, basketball, volleyball, or hockey).

\section{Procedures}

Skinfolds were measured using Harpenden calipers (British Indicators, Luton, UK) at eight landmarked sites on the right side of the body, according to standard procedures (ISAK, 2001). The sites were the triceps (midacromiale-radiale, posterior, and vertical), subscapular $(2 \mathrm{~cm}$ from the inferior angle of the scapula, oblique), biceps (midacromiale-radiale, anterior, and vertical), iliac crest (superior to the iliocristale on ilio-axilla line, near-horizontal), supraspinale (intersection of the iliocristale horizontal line with an iliospinale-anterior axilla, oblique), abdominal ( $5 \mathrm{~cm}$ to the right of the midpoint of the navel), thigh (midway between the inguinal fold and anterior patella on the anterior surface, measured sitting, parallel with the limb), and medial calf (medial aspect at the level of maximum calf girth, vertical).

\section{Statistical methods}

The relationship between skinfold calliper readings $\left(S_{i j}\right)$ (at eight sites, $\mathrm{i}=1,2, \ldots, 8$, and between the four sports plus controls $\mathrm{j}=1,2, \ldots, 5$ ) and body size (using either body mass $(\mathrm{M})$, stature $(\mathrm{H})$, or both) was explored collectively using multivariate analyses of covariance (MANCOVAs), and individually (for each site) with follow-up ANCOVAs. The sum-of-eight skinfolds were also analyzed using ANCOVA. These analyses investigated differences in $\mathrm{S}_{\mathrm{ij}}$ between sports, using the following proportional allometric models to describe the covariates (Nevill et al., 2004):

$$
\begin{aligned}
& S_{\mathrm{ij}}=\mathrm{a}_{\mathrm{ij}} \cdot \mathrm{H}^{\mathrm{b}_{1 i}} \cdot \exp \left(\mathrm{c}_{\mathrm{i}} \cdot \operatorname{age}+\mathrm{d}_{\mathrm{i}} \cdot \operatorname{age}^{2}\right), \\
& \mathrm{S}_{\mathrm{ij}}=\operatorname{aij} \cdot \mathrm{M}^{\mathrm{b}_{2 \mathrm{i}}} \cdot \exp \left(\mathrm{c}_{\mathrm{i}} \cdot \operatorname{age}+\mathrm{d}_{\mathrm{i}} \cdot \operatorname{age}^{2}\right), \\
& \mathrm{S}_{\mathrm{ij}}=\mathrm{a}_{\mathrm{ij}} \cdot \mathrm{H}^{\mathrm{b}_{1 i}} \cdot \mathrm{M}^{\mathrm{b}_{2 \mathrm{i}}} \cdot \exp \left(\mathrm{c}_{\mathrm{i}} \cdot \operatorname{age}+\mathrm{d}_{\mathrm{i}} \cdot \operatorname{age}^{2}\right),
\end{aligned}
$$

where $a_{i j}$ is the scaling constant, allowed to vary between sports $(j)$, and $b_{1 i}$ and $b_{2 i}$ are the stature and mass scaling exponents for each site $(i=1,2, \ldots, 8)$, respectively. Note that the eight sites provide the variables for the multivariate analysis, and the four sports plus controls are incorporated within each MANCOVA and ANCOVA. Age was incorporated into the models as a quadratic polynomial 
TABLE 2a. Height $\left(b_{1}\right)$ exponents after adjusting for differences in age

\begin{tabular}{lrr}
\hline & Male & Female \\
\hline Triceps & -0.11 & 0.14 \\
Subscapular & -0.18 & -1.36 \\
Biceps & -0.94 & -1.19 \\
Iliac crest & -0.26 & 0.71 \\
Supraspinale & 0.04 & -0.76 \\
Abdominal & -0.02 & -0.14 \\
Front thigh & -0.06 & -0.40 \\
Medial calf & -0.45 & 0.40 \\
\hline
\end{tabular}

(using both age and age $^{2}$ terms) to accommodate the likelihood that skinfold calliper readings may decline during adolescence, to reach a minimum sometime in early adulthood and increase thereafter.

Both skinfolds and BMIs are known to be positively skewed (Heath and Carter, 1967; Nevill and Holder, 1995, respectively). Fortunately, the proportional allometric models above can be linearized with a log-transformation that will naturally overcome the positive skewness in such data. The MANCOVA with follow-up univariate ANCOVAs can then be used to estimate the effects of "sport," having controlled for differences in these confounding covariates of body size (either stature, mass, or both), age, and age ${ }^{2}$. Due to the known sex differences in body fat mass and its distribution, these analyses were conducted separately for male and female subjects. When an ANCOVA main-effect difference between sports was detected, pairwise comparisons were made, using the Bonferroni adjustment for multiple comparisons.

\section{RESULTS \\ Relationship between skinfold measurements and stature $(\mathrm{H})$}

The MANCOVAs identified a significant difference in skinfold measurements at the eight sites between sports for both male (Wilks' lambda $=0.710, \mathrm{~F}_{32,1,005}=3.053, P$ $<0.001$ ) and female (Wilks' lambda $=0.750, \mathrm{~F}_{32,647}=$ $1.64, P=0.016$ ) subjects. The stature covariates from the MANCOVAs were found not to be related to skinfold measurements for male subjects $(P>0.05)$, but significantly related to skinfold measurements for female subjects $(P=0.001)$. The fitted stature exponents at all eight sites for male and female subjects are given in Table 2a. Note that the majority of exponents in this population are negative, contradicting the usual assumption that taller people have greater skinfold measurements, and hence calling into question the necessity of making the traditional adjustment $170.18 / \mathrm{H}(\mathrm{cm})$ (Carter and Heath, 1990).

\section{Relationship between skinfold measurements and body mass (M)}

As before, the MANCOVAs identified a significant difference in skinfold measurements between sports for both male $(P<0.001)$ and female $(P<0.05)$ subjects. Not surprisingly, the body-mass covariates from the MANCOVAs were found to be significantly related to skinfold measurements for male and female subjects $(P<0.001)$. The fitted mass exponents at all eight sites for male and female subjects are given in Table $2 \mathrm{~b}$. Interestingly, the majority of mass exponents are greater than unity, especially in sites located in the central regions (supraspinale, iliac crest,
TABLE 2b. Mass $\left(b_{2}\right)$ exponents after adjusting for differences in age

\begin{tabular}{lcc}
\hline & Male & Female \\
\hline Triceps & 0.70 & 1.07 \\
Subscapular & 0.91 & 0.92 \\
Biceps & 0.33 & 1.17 \\
Iliac crest & 1.24 & 1.73 \\
Supraspinale & 1.36 & 1.45 \\
Abdominal & 1.31 & 1.29 \\
Front thigh & 0.69 & 0.90 \\
Medial calf & 0.64 & 1.37 \\
\hline
\end{tabular}

and abdominal), and in particular for female subjects. Note that if skinfold thicknesses increase in proportion to body size (obeying the principle of geometric similarity; see Nevill et al., 2004), these mass exponents should increase as a linear dimension of body size, or in proportion to $\mathrm{M}^{0.33}$.

\section{Relationship between skinfold measurements and stature $(\mathrm{H})$ and mass $(\mathrm{M})$}

The MANCOVAs incorporating both stature and body mass identified significant differences in skinfold measurements between sports for male subjects (Wilks' lambda $=0.756, \mathrm{~F}_{28}, 982=2.83, P<0.001$ ) but nonsignificant differences between sports for female subjects (Wilks' lambda $=0.818, \mathrm{~F}_{28,632}=1.30, P>0.05$ ). The Bonferroni pairwise comparisons between sports of male subjects identified strength and speed athletes as having the lowest skinfolds: these were significantly lower than controls at all eight sites $(P<0.01)$, and significantly lower than endurance athletes at the subscapular, biceps, front-thigh, and calf sites $(P<0.05)$. The ANCOVA analysis of the sum-of-eight skinfolds identified significant differences between sports for both male $(P<0.001)$ and female $(P<$ 0.05 ) subjects. Based on the sum-of-eight skinfolds, the male strength and speed athletes have $(78.3-53.0) / 78.33$ $=32 \%$ and $(78.3-60.13) / 78.33=23 \%$ lower skinfold measurements, respectively, compared with controls. Similarly, the female strength athletes have $(94.6-67.3) / 94.6$ $=28.9 \%$ lower skinfold measurements compared to controls. Differences in skinfold measurements between athletic groups, having adjusted for differences in body size and age, are given in Table $3 a, b$ for male and female subjects, respectively.

The mass and stature covariates from the MANCOVAs were found to be significantly related to skinfold measurements for both male and female subjects $(P<0.001)$. The fitted mass and stature exponents at all eight sites for male and female subjects are given in Table 2c. Note that empirically derived stature $\left(\mathrm{H}^{\mathrm{b}_{1}}\right)$ and mass terms $\left(\mathbf{M}^{\mathrm{b}_{2}}\right)$ from Equation (3) can be expressed as $\mathrm{M}^{\mathrm{b}_{2}} \mathrm{H}^{\mathrm{b}_{1}}=\left(\mathrm{M} / \mathrm{H}^{-\mathrm{b}_{1}}\right.$ $\left.\mathrm{b}_{2}\right)^{\mathrm{b}_{2}}$, a ratio not dissimilar to $\mathrm{BMI}=\mathrm{M} /\left(\mathrm{H}^{2}\right)$, provided $\mathrm{b}_{1} /$ $\mathrm{b}_{2}$ is approximately -2 .

This assumption appears reasonable at the majority of sites for both male and female subjects (Table 2c), suggesting that a power function of $\mathrm{BMI}^{\mathrm{b}_{2}}$ is an acceptable bodysize index associated with skinfold measurements (Fig. 1). However, on closer inspection, this assumption might be a little premature, given that the $95 \%$ confidence interval for the eight male $b_{1} / b_{2}$ values (from -2.623 to -2.092 ) precludes -2 . In contrast, the $95 \%$ confidence interval for the eight female $b_{1} / b_{2}$ values was from -2.489 to -1.958 , encompassing the traditional $\mathrm{BMI}$ value -2 . 
TABLE 2c. Height $\left(b_{1}\right)$ and mass $\left(b_{2}\right)$ exponents and empirically derived BMI height exponents $\left(b_{1} / b_{2}\right)^{1}$ after adjusting for differences in age

\begin{tabular}{lccccr}
\hline & \multicolumn{3}{c}{ Male } & \multicolumn{2}{c}{ Female } \\
\cline { 2 - 5 } & Mass $\left(\mathrm{b}_{2}\right)$ & Height $\left(\mathrm{b}_{1}\right)$ & $\left(\mathrm{b}_{1} / \mathrm{b}_{2}\right)$ & & Meight $\left(\mathrm{b}_{1}\right)$ \\
\hline Triceps & 1.35 & -3.02 & -2.24 & 1.84 & -3.69 \\
Subscapular & 1.77 & -4.01 & -2.26 & 2.11 & -2.74 \\
Biceps & 0.99 & -3.08 & -3.10 & 2.50 & -2.00 \\
Iliac crest & 2.42 & -5.47 & -2.27 & 2.78 & -2.59 \\
Supraspinale & 2.53 & -5.41 & -2.14 & 2.83 & -5.07 \\
Abdominal & 2.45 & -5.30 & -2.17 & 2.32 & -6.64 \\
Front thigh & 1.30 & -2.88 & -2.20 & 1.72 & -4.96 \\
Medial calf & 1.38 & -3.43 & -2.48 & 2.27 & -3.98 \\
\hline
\end{tabular}

${ }^{1}$ Obtained by expressing $\mathrm{M}^{\mathrm{b}_{2}} \mathrm{H}^{\mathrm{b}_{1}}=\left(\mathrm{M} / \mathrm{H}^{-\mathrm{b}_{1} / \mathrm{b}_{2}}\right)^{\mathrm{b}_{2^{\prime}}}$.

TABLE 3a. Skinfold thicknesses and percent body fat at eight sites for male subjects adjusted at mean body mass (81.5 kg), stature $(181.1 \mathrm{~cm})$, and age $(27.9 \text { years })^{1}$

\begin{tabular}{lccrrr}
\hline \multicolumn{1}{c}{ Sites } & Control & Endurance & Games & Speed & Strength \\
\hline Triceps & 10.10 & 9.43 & 9.44 & 7.98 & 6.43 \\
Subscapular & 11.49 & 11.06 & 10.88 & 9.66 & 9.49 \\
Biceps & 4.69 & 4.44 & 4.37 & 3.50 & 3.44 \\
Iliac crest & 13.60 & 12.35 & 12.30 & 10.27 & 9.23 \\
Supraspinale & 8.55 & 7.83 & 7.72 & 6.77 & 6.03 \\
Abdominal & 15.63 & 15.19 & 14.55 & 11.56 & 9.53 \\
Front thigh & 14.28 & 14.21 & 12.57 & 10.38 & 8.85 \\
Medial calf & 9.06 & 8.00 & 8.10 & 6.16 & 6.01 \\
Sum & 78.33 & 74.51 & 71.82 & 60.13 & 53.00 \\
Percent & 11.3 & 10.7 & 10.2 & 8.2 & 7.00 \\
$\quad$ body fat & & & & & \\
\hline
\end{tabular}

${ }^{1}$ Percent fat calculations based on new regression of $\Sigma 8$ skinfolds against DXA (dual X-ray absorptiometry) derived fat mass, using data from Stewart and Hannan (2000b).

The MANCOVA also confirmed significant negative age and positive age ${ }^{2}$ terms for male and female subjects $(P<$ 0.05). Using elementary differential calculus, we can estimate that athletes' skinfold measurements tend to reach a minimum in the late 20 s for male and in the early 30 s for female subjects.

However, having controlled for differences in body size (i.e., approximate BMI) and age, sporting differences in skinfolds (for males) and sum-of-eight skinfolds (for male and female subjects) still exist, e.g., athletic groups such as strength-trained athletes will have significantly lower skinfold measurements.

\section{DISCUSSION}

The first insight obtained from the above results is that taller subjects in the present sample did not have greater skinfold measurements. Table $2 \mathrm{a}$ confirms that when modeling skinfold thicknesses, the stature exponent was negative in the majority of sites for both male and female subjects. These exponents indicate that taller subjects will have less rather than more adiposity, a finding that seriously questions the use of the traditional stature adjustment 170.18/stature. Of course, this observation may be specific to our sample/population, acknowledged as being relatively athletic. However, this finding does cast some doubt on the need to make the traditional stature adjustment of skinfolds (Carter and Heath, 1990), especially for athletic populations, and suggests that further exploration into the skinfold-stature relationship is warranted, using proportional allometric models (Equation 1).
TABLE 3b. Skinfold thicknesses at eight sites for female subjects adjusted at mean body mass $(60.6 \mathrm{~kg})$, stature $(166.9 \mathrm{~cm})$, and age $(29.2 \text { years })^{1}$

\begin{tabular}{lrrrrr}
\hline \multicolumn{1}{c}{ Sites } & Control & Endurance & Games & Speed & Strength \\
\hline Triceps & 16.11 & 15.74 & 15.41 & 13.94 & 11.29 \\
Subscapular & 11.68 & 11.32 & 10.03 & 9.94 & 8.38 \\
Biceps & 6.78 & 5.93 & 6.31 & 5.99 & 4.51 \\
Iliac crest & 12.11 & 11.36 & 11.91 & 10.44 & 9.43 \\
Supraspinale & 8.95 & 8.30 & 8.69 & 7.49 & 6.30 \\
Abdominal & 15.08 & 13.91 & 15.24 & 12.44 & 8.88 \\
Front thigh & 23.92 & 23.57 & 23.74 & 21.19 & 18.46 \\
Medial calf & 13.89 & 13.61 & 13.65 & 13.91 & 10.88 \\
Sum & 94.62 & 90.13 & 91.32 & 81.43 & 67.25 \\
Percent body fat & 19.64 & 19.01 & 19.40 & 17.39 & 14.79 \\
\hline
\end{tabular}

${ }^{1}$ Percent fat calculations based on predictions of Jackson et al. (1980), based on $\Sigma 4$ skinfolds.
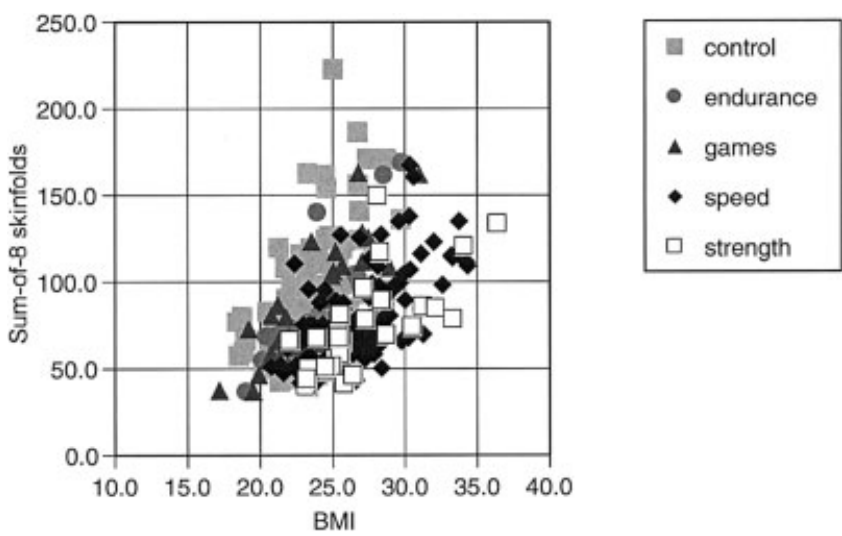

Fig. 1. Relationship between sum-of-eight skinfolds and BMI for male subjects. For a given BMI, speed, and strength, athletes' sums of skinfolds are systematically lower than controls $(P<0.001)$.

The second noteworthy finding confirms that skinfolds increase at a much greater rate relative to mass than that assumed by geometric similarity. Under the assumption that human physiques are geometrically similar to each other, linear dimensions such as heights or limb girths should be proportional to $\mathrm{M}^{0.33}$. Since raised skinfold thicknesses are part of the radius of a girth measurement (assuming that the skinfold caliper reading $\mathrm{S}_{\mathrm{ij}}$ is twice the adipose tissue thickness), skinfold measurements should also be proportional to a linear dimension of body size, $\mathrm{M}^{0.33}$, assuming that subjects are geometrically similar to each other. 
However, the mass exponents reported in Table $2 \mathrm{~b}$ clearly contradict this assumption. Indeed, with the exception of male biceps, all skinfold caliper readings increased at a much greater rate relative to body mass than that expected assuming geometric similarity (e.g., mass exponents ranged from being 2 -fold greater for the male front thigh to 5 -fold greater for female iliac crest). These findings confirm that as people get heavier, gains in skinfolds make up the overwhelming contribution to increases in body mass, a finding that provides further evidence that human physiques are not geometrically similar (Nevill et al., 2004; Ross and Wilson, 1974).

The third insight obtained from the present study was that the best body-size index associated with skinfold measurements was a stature-adjusted BMI, M/ $\mathrm{H}^{\mathrm{b}_{1} / \mathrm{b}_{2}}$, not too dissimilar to the traditional $\mathrm{BMI}=\mathrm{M} / \mathrm{H}^{2}$, i.e., the ratio $b_{1} / b_{2}$ was either greater than or approximately equal to -2 at the majority of sites for both male and females (Table 2c). The fact that the $95 \%$ confidence interval for male values $\left(b_{1} / b_{2}\right)$ exceeds -2 does cast some doubt on whether the traditional BMI is the optimal statureadjusted body mass index to best describe adiposity.

However, what was more disturbing about these results was that sporting differences in skinfold measurements still persist among male and female subjects after controlling for differences in body size (approximate BMI) and age. For example, the male strength- and speed-trained athletes have significantly lower sum-of-eight skinfold measurements (32\% and $23 \%$, respectively) compared with controls, after adjusting for differences in statureadjusted body mass and age (i.e., assuming that BMI and age are the same for all groups). These lower sum-of-eight skinfold measurements, shown in Figure 1, will translate into significantly lower percent body fat, $38.1 \%(=(11.3-$ $7.0) / 11.3)$ and $27.4 \%(=(11.3-8.2) / 11.3)$ for the male strength and speed athletes, respectively, compared to controls. Similarly, the lower sum-of-eight skinfold measurements for female strength athletes will also represent significantly lower percent body fat, $24.6 \% \quad(=(19.6-$ 14.8)/19.6), compared to female controls.

Similar concern was raised in a large study by Ross et al. (1988) when reporting the relationship between BMI and skinfolds, girths, and bone breadths in a large crosssectional sample from the Canadian YMCA Life Program. Combining male and female data $(\mathrm{n}=18,875)$, a table was constructed reporting the percentile sum of five skinfolds, and the BMI range of individuals. The study highlighted the potential for misclassification of individuals, and found that BMI correlated better with corrected girths (limb girth, from which the skinfold multiplied by pi is subtracted) and bone breadths than with skinfold totals. Across all groups, the overall correlation of BMI with skinfold total was 0.50 , improving to $0.60-0.71$ and $0.63-$ 0.73 for men and women, respectively, when categorized by age and sex. In the present study, the combined correlation between BMI and sum-of-eight skinfolds for male and female subjects was only 0.27 , with correlations for male and female subjects separately being 0.48 and 0.72 , respectively.

The lower correlation in the present study may indicate greater physique "specialization" of this sample via a process of self-selection into sports in which individuals are likely to excel, coupled with morphological changes in muscle and adipose tissue reflecting the training environment. Thus, successful athletes in certain sports may have skeletal proportions which may not be typical of the reference population from which they are derived (Norton and
Olds, 2001). Muscle mass acquired during the training process will obey the law of specificity (Kraemer et al., 2002), and fat mass in physically active individuals will not only reflect energy balance but also may display a changed pattern with physical fitness which may indicate preferential lipolysis of abdominal fat (Nindl et al., 1996) and lower skinfolds in this region as a consequence. However, our current understanding of metabolism suggests that athletes from different sporting disciplines, while exhibiting low torso fat, do not alter fat patterning in any sport-specific way (Stewart and Hannan, 2000a). Thus, while a principle of specificity may apply to muscle development, a principle of "generality" appears to prevail in physical activity of different forms in terms of fat distribution.

While the significantly lower skinfold measurements of strength and speed athletes compared to controls of the same body size (approximate BMI) may appear unexpected, perhaps they are not too surprising. Comparing two subjects with the same stature and mass (and hence $\mathrm{BMI}$ ), the one with a greater proportion of muscle must automatically have less adiposity. We recognize that the majority of subjects in the strength group were limited by total mass to specific weight categories for competition, and as a result had a dual interest in being both muscular and lean. Nevertheless, the above findings confirm the dangers of using BMI in epidemiological studies, especially when a significant proportion of subjects come from an athletic population. Clearly, when monitoring trends in fatness over time and between populations, a more valid method of assessing fatness (less prone to systematic bias) is likely to be obtained using surface anthropometry such as raised skinfold measurements.

\section{CONCLUSIONS}

Skinfolds increase at a much greater rate relative to body mass than that assumed by geometric similarity (e.g., mass exponents ranged from being 2 -fold greater for the male front thigh to 5-fold greater for the female iliac crest). However, taller subjects had less rather than more adiposity, calling into question the use of the traditional skinfoldstature adjustment, 170.18/stature. The best body-size index reflective of skinfold caliper measurements was a stature-adjusted body mass index, similar to the BMI. However, sporting differences in skinfold thickness persisted after controlling for differences in body size (approximate BMI) and age. These results cast serious doubts on the validity of BMI to represent adiposity accurately and its ability to differentiate between populations, especially when such populations contain different proportions of athlete subjects. These findings suggest that a more valid (less susceptible to systematic bias) assessment of fatness will be obtained using surface anthropometry such as skinfolds taken by experienced practitioners following established procedures.

\section{ACKNOWLEDGMENTS}

The authors thank Barry Ridge, Lindsay Carter, Grant Tomkinson, Shelley Kay, and Alex Mavroeidi for permission to use their data in these analyses. We also thank the Editor and both referees for positive, helpful suggestions when revising the manuscript. 


\section{LITERATURE CITED}

Carter JEL, Heath BH. 1990. Somatotyping-development and applications. Cambridge: Cambridge University Press.

Cole TJ. 1991. Weight-stature indices to measure underweight, overweight and obesity. In: Himes JH, editor. Anthropometric assessment of nutritional status. New York: Wiley-Liss. p 83111.

Davey RC, Stanton R. 2004. The obesity epidemic: too much food for thought? Br J Sports Med 38:360-363.

Heath BH, Carter JEL. 1967. A modified somatotype method. Am J Phys Anthropol 27:57-74.

Heyward VH, Stolarczyk LM. 1996. Body composition and ethnicity: applied body composition assessment. Champaign, IL: Human Kinetics. p 173-185.

Hortobagyi T, Israel RG, O’Brien KF. 1994. Sensitivity and specificity of the Quetelet Index to assess obesity in men and women. Eur J Clin Nutr 48:369-375.

ISAK. 2001. International standards for anthropometric assessment. Underdale, South Australia: ISAK.

Jackson AS, Pollock ML, Ward A. 1980. Generalized equations for predicting body density of women. Med Sci Sports Exerc 12:175-182.

Jeffreys M, McCarron P, Gunnell D, McEwen J, Smith GD. 2003. Body mass index in early and mid-adulthood, and subsequent mortality: a historical cohort study. Int J Obes 27: 1391-1397.

Kraemer WJ, Adams K, Cafarelli E, Dudley GA, Dooly C, Feigenbaum MS, Fleck SJ, Franklin B, Fry AC, Hoffman JR, Newton RU, Potteiger J, Stone MH, Ratamess NA, TriplettMcBride T. 2002. Joint position statement: progression models in resistance training for healthy adults. Med Sci Sports Exerc 34:364-380.

Nevill AM, Holder RL. 1995. Body mass index: a measure of fatness or leanness? Br J Nutr 73:507-516.

Nevill AM, Stewart AD, Olds T, Holder RL. 2004. Are adult physiques geometrically similar? The dangers of allometric scaling using body mass power laws. Am J Phys Anthropol 124:177-182.

Nindl BC, Friedl KE, Marchitelli LJ, Shippee RL, Thomas CD, Patton JF. 1996. Regional fat placement in physically fit males and changes with weight loss. Med Sci Sports Exerc 28: 86-793.

Norton K, Olds T. 2001. Morphological evolution of athletes over the 20th century-causes and consequences. Sports Med 31: 763-783.

Popkin BM. 2001. The nutrition transition and obesity in the developing world. J Nutr 131:871-873.

Ross WD, Wilson NC. 1974. A stratagem for proportional growth assessment. Acta Paediatr Belg 28:169-182.

Ross WD, Crawford SM, Kerr DA, Ward R, Bailey DA, Mirwald RM. 1988. Relationship of the body-mass index with skinfolds, girths, and bone breadths in Canadian men and women aged 20-70 Years. Am J Phys Anthropol 77:169173.

Stewart AD, Hannan J. 2000a. Sub-regional tissue morphometry in male athletes and controls using dual X-ray absorptiometry (DXA). Int J Sport Nutr 10:157-169.

Stewart AD, Hannan WJ. 2000b. Prediction of fat and fat-free mass in male athletes using dual X-ray absorptiometry as the reference method. J Sports Sci 18:263-274. 